\title{
Constituent Market Orientation and Ownership of Virtual Marketplaces
}

\author{
Dr. Brynjulf Tellefsen \\ Norwegian School of Management (BI), Oslo, Norway \\ brynjulf.tellefsen@bi.no \\ Dr. Terence Love \\ Curtin University, Perth, Western Australia \\ tlove@love.com.au
}

\begin{abstract}
This paper applies new empirically based knowledge in the area of Constituent Market Orientation to a seven-element taxonometric model of Virtual Organisation. The most effective distribution of resources and management attention in the development of combinations of real and virtual business solutions is identified for each of the seven alternative configurations. The paper concludes with a list of key concepts that offer owners and managers of virtual organisations analytically based heuristics founded on cross-sectoral empirical research.
\end{abstract}

Keywords: Virtual Organisations, e-Business Marketplaces, Management, Constituents, Market Orientation, Organisational learning

\section{Introduction}

There are few studies of the innovative developments resulting in virtual organisations. Those managing virtual organisations can draw on very little information and empirical knowledge from observing successful virtual organisations in similar circumstances. The alternative, managing on the basis of theoretical models of virtual organisations, is also difficult because theory development in this area has been limited and not yet well grounded in large-scale empirical research.

The purpose of this paper is to describe an approach to understanding and managing virtual organisations that is grounded in solid empirical research on Constituent Market Orientation, and based on theoretical models from a large group of researchers dedicated to e-business research.

The paper applies Constituent Market Orientation research findings and theories (see Tellefsen, 1995 and 1999) to a seven element model of virtual organisations developed by Burn and associates (see, for example, Burn and Barnett, 1999, Burn et al., 1999, Burn and Tetteh, 2000, Burn et al, 2002, Lethbridge, 2001, Marshall et al., 2001). The paper concludes with a list of key concepts that offer owners and managers of virtual organisations analytically based heuristics.

\section{Background}

When constructing a business solution, a variety of constituencies and stakeholders determine an idea's market value, effectiveness, and efficiency. These include owner capital and loan financing markets, labour markets, downstream markets, collaborative markets, upstream markets including suppliers, market regulators such as industry associations, governments, 
general influencers like the media and the public, as well as organisation-internal markets. Market-oriented leaders direct their attention and efforts towards these constituent markets to maximise a business unit's competitiveness. Combined, the above distribution of attention forms the 'constituent market orientation' of an organisation.

Many e-commerce initiatives fail because the owners and top management team of an organisation do not see the whole picture, or the significance of all the constituent relationships that need to be developed. What are needed in most cases are more sophisticated models of leadership and the management of combinations of real and virtual world business ideas. These models must provide the theoretical mechanisms to support the inclusion of issues of human values, motivations, interactions, feelings, moral and legal constraints, political machinations, power manipulations, as well as the social and legal contracts that form part of the sociology and organisational solutions supporting the realisation of a particular business idea. In addition, models are also needed to describe how an individual's membership of different organisational groups, internal and external, and their role in each of these groups, shape their learning and behaviour, and thereby their contribution to innovation.

Tellefsen $(1999,1995)$ has undertaken extensive research justifying a top management led programmatic learning effort combined with organisational architectural design of natural learning based on feedback from the constituents ('market-back') theory of Constituent Market Orientation. The research findings are based on information provided by 235 CEOs, 244 market managers, 188

purchasing managers, 163 personnel managers, 179 union representatives, 154 PR managers, and 175 lobbying managers. The original hypotheses were aimed at conventional larger organisations. His findings, however, indicate that the outcomes of this Constituent Market Orientation research are applicable more broadly.

This paper outlines how Tellefsen's Constituent Market Orientation findings, theories and analyses can be used to reveal underlying forces and factors that impact on the success of different forms of virtual organisation. The analyses presented in this paper use as a framework an extended version of the taxonometric model of virtual organisations developed at the We-B Research Centre in the School of Management Information Systems at Edith Cowan University.

\section{Overview of Constituent Market Orientation}

Market orientation is essentially a theory of market-driven organizational learning and innovation. An individual learns through interacting with his or her environment. The closer the interaction with a particular part of the environment, the more the individual learns about that part. If an individual has no direct interaction with a part of his or her environment, that part will become unknown and invisible. Commonly, the constituent market orientation of an individual becomes unbalanced and results in increased focus on some constituents and partial ignorance of other constituents.

The configuration of an individual's group membership is the most important factor in their orientation. We are social beings. Intense learning occurs primarily in face-to-face groups. Groups with frequent contacts and internal double and triple-loop learning establish a strong culture with common beliefs, values, goals, priorities, language, habits and recognition patterns. In larger group contexts, they form a sub-culture. The number, type and heterogeneity of an individual's cultural traits (often referred to as the individual's personality) depends on the number and types of social groups he or she belongs to. Each 
individual's consciousness is limited, tending to routinize behavior, and result in focusing on a limited set of social relations. When an individual is preoccupied with something - due to habits or previous learning of beliefs, values, priorities and goals - other things are unattended, invisible or not comprehended.

Crossan et al (1999) say the same limitations apply to groups sharing mental frames, paradigms, observations and experiences. These limitations, combined with group-wise double-loop learning; result in many groups developing distinct sub-cultures that are often homogenous and stable. These factors interact with other organisational, management and leadership factors in significant ways. An organization institutionalizes what tasks are to be carried out by whom, who works with whom, and the rules and intensity of interactions. The nature and structure of the institutionalization has a profound impact on the emergence of distinct sub-cultures within industrial clusters, networks of cooperating firms, single firms, and inter- and intra-organizational work-groups. The tighter group-internal relations are, and the looser the group-external relations are, the stronger the sub-cultures of individual groups become.

Typically, firms that organise their activities in cross-functional and inter-institutional ad hoc project teams, tend to develop a more homogeneous firm level culture than firms that organise people in functional specialisations with mainly repetitive activities. The choice of process supporting an organisation's development is partly determined by the nature of the business, and partly by the preferences and experiences of the significant actors within the organisation.

Organizations that consist of heterogeneous groups with strong sub-cultures become extremely difficult to govern and lead. Common language, perceptions, values, experiences, goals and habits are weak. Performance and behavior become unpredictable for the organization as a whole, and the organization will not be able to develop a common identity and image. The challenge to the leadership, therefore, is to establish learning loops that are programmatic and led from the center of power. This is especially important if the tasks are repetitive and in need of great expertise. The purpose of these programmatic learning loops, is to establish common purpose, values, and objectives. They must also result in a common understanding of language, facts, and the environment, with its internal processes and structure, constituents and stakeholders. From a strategic point of view, it is also essential to establish definition between 'us' and 'others': the limits and borders of the organization, its partners and alliances, and its competition. In order to establish a strong common culture in the organization, the common elements established by the leadership must be communicated to all members of the organization, and be implemented in all decisions regarding leadership style, organizational architecture, structures and processes, strategies, operations, services and products, and be reflected in all external communication with the constituents. An alternative, to this organizational approach to producing and exchanging values in the sub-groups of an organisation, is the market solution of distance and freedom of choice among the actors. Resource-based and agent-based theories of networks have explored the feasibility and economics of these alternatives: administrative versus market solutions of exchange (Conner, 1991, Dahlstrom and Nygaard, 1999, Heide, 1994).

Knowledge management is a key factor in the above issues (see, for example, Prusak, 1997). Learning theory distinguishes between tacit and explicit knowledge. Explicit knowledge can be communicated through a common language, which includes the meaning and feelings attached to body language, pictures, sound, and any form of symbols including written language. Knowledge can also be tacit, and this can occur at several levels: individual, work group, network, firm, industry, language group, etc. In the context of e-business, a prerequisite for an e-based business solution is that knowledge received via an electronic network is explicit between the senders and the receivers. This implies that tacit knowledge 
cannot become part of the e-commerce systems interface with users, although it has a role in developing and understanding the non-visible parts of an e-commerce solution.

Virtual networks have the most to offer if processes are repetitive and easily reduced to very explicit and fixed code. This is exactly the situation where the organisation tends to be organised around permanent, expertise-focused functional teams. The need for management to think in terms of cross-functional and cross-institutional learning is of particular importance in order to promote a cohesive firm-level common culture. Otherwise the leadership may either lose its ability to govern the organisation, or have to resort to an authoritative and controlling leadership style. Authoritative and controlling leadership does not work well in innovative and knowledge-based organisations that often underpin the emerging e-commerce firms. Market-oriented leadership and management style seems to offer the best promise for a productive solution to this dilemma.

\section{Four key processes in business idea implementation}

E-systems have advantages in generating and distributing data, but limitations in interpretation of the data necessary for generating learning that can lead to adaptive and generative innovation. E-networks, as system enablers for gathering and disseminating information, have limited usefulness in governance and leadership processes, and those exchange processes that involve physical products and services requiring problem solving or the use of tacit knowledge. The leaders of an e-business therefore have to construct and manage four parallel systems in addition to the system for current operations (Tellefsen, 1995). To establish and maintain a holistic business idea the leadership group needs to use:

1. The power system: Ownership that establishes who 'we' are, social legitimacy, authority to make decisions, risk-taking, the distribution of values gained and consumed (including financing of investments, distribution of revenues and costs, liquidity and profits)

2. Internal driving forces: Use the power system to develop shared beliefs, purpose (mission), values, attitudes, vision and objectives among members of the organization

3. Strategy making processes: The processes and systems for developing organization-wide agreement on who 'we' are, our image, who we want to relate to and exchange values with (the stakeholders and alliance partners), who the 'others' are (competition and other constituents), how to compete (defining moral and wanted behavior) and with what (technology and know-how).

4. Operative management and systems: Management processes and procedures, including methods for task delegation, solving disputes, accountability, value production, value distribution, delegated risk-taking, Development and integration of real-world and virtual systems of operations.

How these internal organizational factors influence the extent of market-driven learning, and how the resulting constituent market orientation influences various organizational outcomes is illustrated in figure 1. 


\section{FIGURE 1 : A model of constituent orientation}

Functional Managers

Confli ct/ comn ect edness with

other functions, departments

and hierar cly levels.

\section{ANTECEDENTS}

The CEO

Risk taking, Reorientation

All n

Perso

Senior management signals

Rel ative pri ority of constituents

\section{CONSTITUENT ORIENTATION}

Fumction al Man agers

The

Mark et ori ent ati on tow ar dtheir own constituent measured

Mark as gath ering, diss eminating, and rea cting on intel ligence

CONSTITUENT MODERA TORS

\section{Gowmment}

Lobbying competiti on int ensity

The firm's i mportance for the govermment

Regul ati on changes in the firm's industry

\section{Customes}

Turbulen ce among customers

Competi tive intensity among customers

\section{Supplers}

Turbulen ce among suppli ers

Competi tive intensity a mong suppliers

Differ entiati on betw een suppliers

\section{Media}

Turbulen ce among me dia

Competition to get into medi a

Avail abi lity of media

Medi a kn ow edge in the industry

\section{Emploves}

Turbulen ce in the empl oyment market

Empl oyment competitive int ensity

Negotiation power of empl oyees

Negoti ation power of union

represent ati ves

Gover mm ent infl uen ce on r elations
ORGANIZATION M The CEO

Generic strategic choic

Lobbying manager

Dependence on govern

Ability to influence tor

Marketing manager

Technol ogical turbuler Ability to influence top Centralization of mark

Purehasing monager

Time horizon for inves Ability to influence top

\section{PR manager}

Centralization of PR d Ability to influence top

Personnel manager

Turbul ence among em] Recruitment needs

Focus on retaining em! Sal ary level

Centralization of perso Ability to influence tor 
Love, Terence (2003) Constituent market orientation and ownership of virtual marketplaces, Logistics Information Management 16(1):8-17.

All e-business and 'virtual' organisations contain, in some form, the roles listed in Figure 1: just like any real-world organization. In addition to internal management factors, the history, culture and competitive climate of the industrial cluster influence the degree of market-driven learning that takes place within all members of a cluster. Three factors influence the profitability, and therefore the strength of market-driven learning towards each separate constituency:

- The intensity of competition to be an exchange partner. How many close substitutes are there among the sellers and the buyers? Monopoly and monopsony alike eliminate the economic gain from a market orientation.

- The differentiability of the competing firms in the eyes of the constituents, e.g., the market-driven learning must be converted to a distinct competitive advantage that cannot easily be copied by the competition.

- The rate of change in the market place, e.g. turbulence in both the supply and the demand constellations in the market. (Tellefsen, 1995).

\section{A seven level taxonomy of forms of virtual organisation}

A 'virtual organisation' is a group of otherwise unconnected organisational components that act together. Virtual organisations have adopted many forms. Research undertaken at the School of MIS, ECU led to a seven-element taxonomy of virtual organisations (Burn et al., 2002). Earlier versions have had six models (Burn and Barnett, 1999, Burn et al., 1999, Burn and Tetteh, 2000, Lethbridge, 2001, Marshall et al., 2001). These classifications have been found to be useful for formulating theory and strategy in the development of e-business networks and for structurally relating 'virtual organisations' to the underlying real organisations.

In the following sections, the implications of findings from constituent market orientation research are drawn out for each of the above organisation types. In the analyses below, the diagrams of the six original types of virtual organisation have been based on those of Lethbridge (2001) with the addition of the 'Virtual Broker' model from Burn et al. (2002). They have been modified slightly to expose additional detail and to correct minor structural flaws in the original models. For example, the virtual face model below emphasises that the customer relates to the virtual face rather than the underlying organisation. The value alliance model below has also been amended to show that customers usually interact only with one end of the value chain.

The analyses undertaken by the authors in understanding virtual organisations through Constituent Market Orientation suggest that the taxonomy can be better understood by putting 'Virtual Broker' at the head of the taxonomy. All the other six elements are particular organisational solutions of this more general form. We find that the 'Virtual space' model suggested by Burn et al. (2002) can be considered to be a special case of the virtual broker model. The seven-element model of virtual organisations discussed below consists of:

- Virtual broker

- Virtual face

- Star alliances 
Love, Terence (2003) Constituent market orientation and ownership of virtual marketplaces, Logistics Information Management 16(1):8-17.

- $\quad$ Market alliances

- Co-alliances

- Value alliances

- $\quad$ Parallel alliances

\section{Virtual Broker}

The service offered is the marketplace itself. Any web portal is potentially a virtual marketplace. There are many forms of traditional marketplaces, like the town-square, the stock market, and various commodity exchanges. Many of these traditional marketplace types have been transformed to mainly virtual forms. If the marketplace is purely virtual, Burn et al. (2002) name it 'Virtual space'.

The owners develop the image and purpose of the marketplace, and provide trade-supporting services to the market actors. The owner/operator also determines the rules of participation, and may select and exclude actors from the exchange. The economics and attractiveness of owning and participating in real and virtual marketplaces have been treated in a series of publications on business models for electronic markets (Amit and Zott, 2001; Dutta and Segev, 1999; Hagel and Armstrong, 1997; Kotha, 1998; Moran and Ghoshal, 1999; Timmers, 1998). It is beyond the scope of this paper to go into these aspects in detail. The owners may use several methods for generating income from the market actors: rental of space, payment for entering and using the portal, take a cut from payments between the actors, sell advertising space, etc.

The owners determine the governance and institutionalisation of the marketplace. There are many examples of different forms of ownership, governance and institutionalisation: e.g. privately owned marketplaces like America Online (AOL), travel booking systems like AMADEUS and SABRE, and industry organisation owned marketplaces like that of the wine producer association of Australia. Some marketplaces have been established with extensive help of the government, and have in many cases obtained legal monopoly, like most national stock exchanges. 


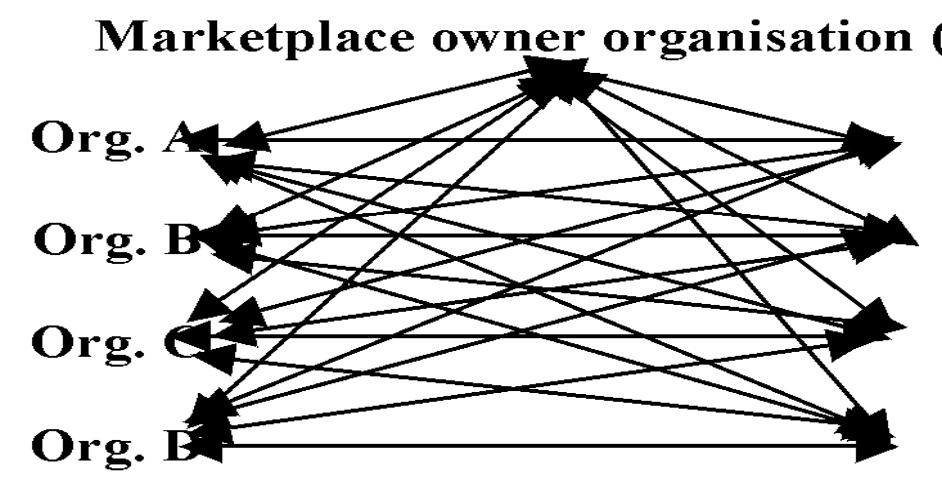

(the bro

Custc

Custc

Custc

Custc

\section{Virtual face}

The 'virtual face' virtual organisation is an alternative representation of a conventional organisation. In most cases of interest, this is an Internet-enabled organisation that works closely with the conventional organisation that underpins it, e.g. Internet banking organisations are commonly 'virtual faces' closely associated with traditional banks. In such an operative systems solution, the traditional core organization carries the whole burden of extending the four processes of holistic business idea implementation (described earlier) to the virtual space. In this situation, two key questions are: 'To what extent can programmed internal and market learning turn tacit knowledge into electronic automation of services and build them into the e-system', and ' To what extent can expert tacit knowledge be reduced to explicit knowledge simple enough to enable network members to use the virtual systems solution?' Those who will not or cannot learn what is needed to use the e-solution will be served by the traditional system. In order to maintain a unitary brand, the virtual and the traditional organizations have to share all cultural traits, artifacts and symbols connected to the personality and image of the brand.

Figure 3: Virtual face

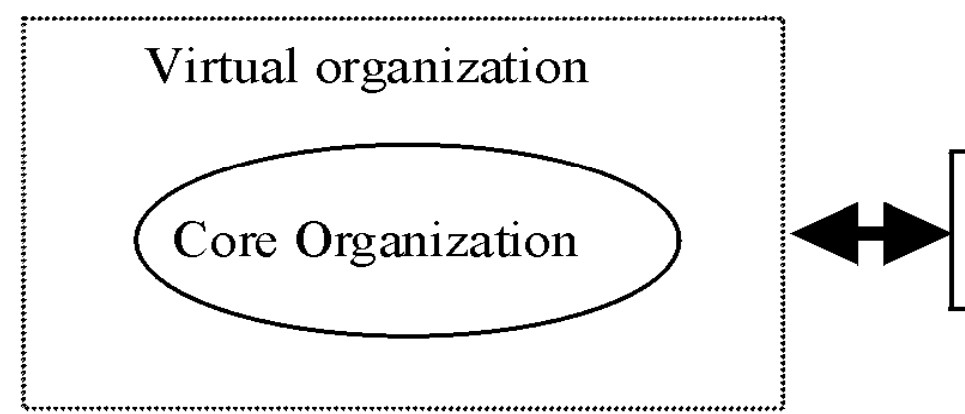


Love, Terence (2003) Constituent market orientation and ownership of virtual marketplaces, Logistics Information Management 16(1):8-17.

\section{Star alliance}

Star alliances occur when a group of otherwise independent organisations are clustered around a single key organisation (the star). This is common in many fields that have a tradition of main contractors and subcontractors.

In a Star alliance, the core organization carries the whole burden of implementing the four processes of business idea implementation. The star builds the personality and image of the corporate brand, as well as the various branded products and services offered to the customers. The star will gain supplier power if its leadership is able to customer-orient its sub-contractors. That requires the star to have a broad constituent orientation that as a minimum contains strong up- and down-stream market-driven learning. It is not important to encourage the development of common cultures between the sub-contractors and the star. Such an effort may in fact be detrimental to the network's ability to produce generative learning needed for proactive behavior and break-through innovation as seen by the customers. The star must put a lot of effort into using the data generated by the e-solution for interpretation and feedback to the sub-contractors to ensure customer orientation of the subcontractors. The supplier organisations A-E below are normally members of several star alliances, exploiting economy of scale in their area of expertise, and providing them with bargaining power to maintain a degree of independence from the core organisation.

\section{Figure 4: Star alliance}

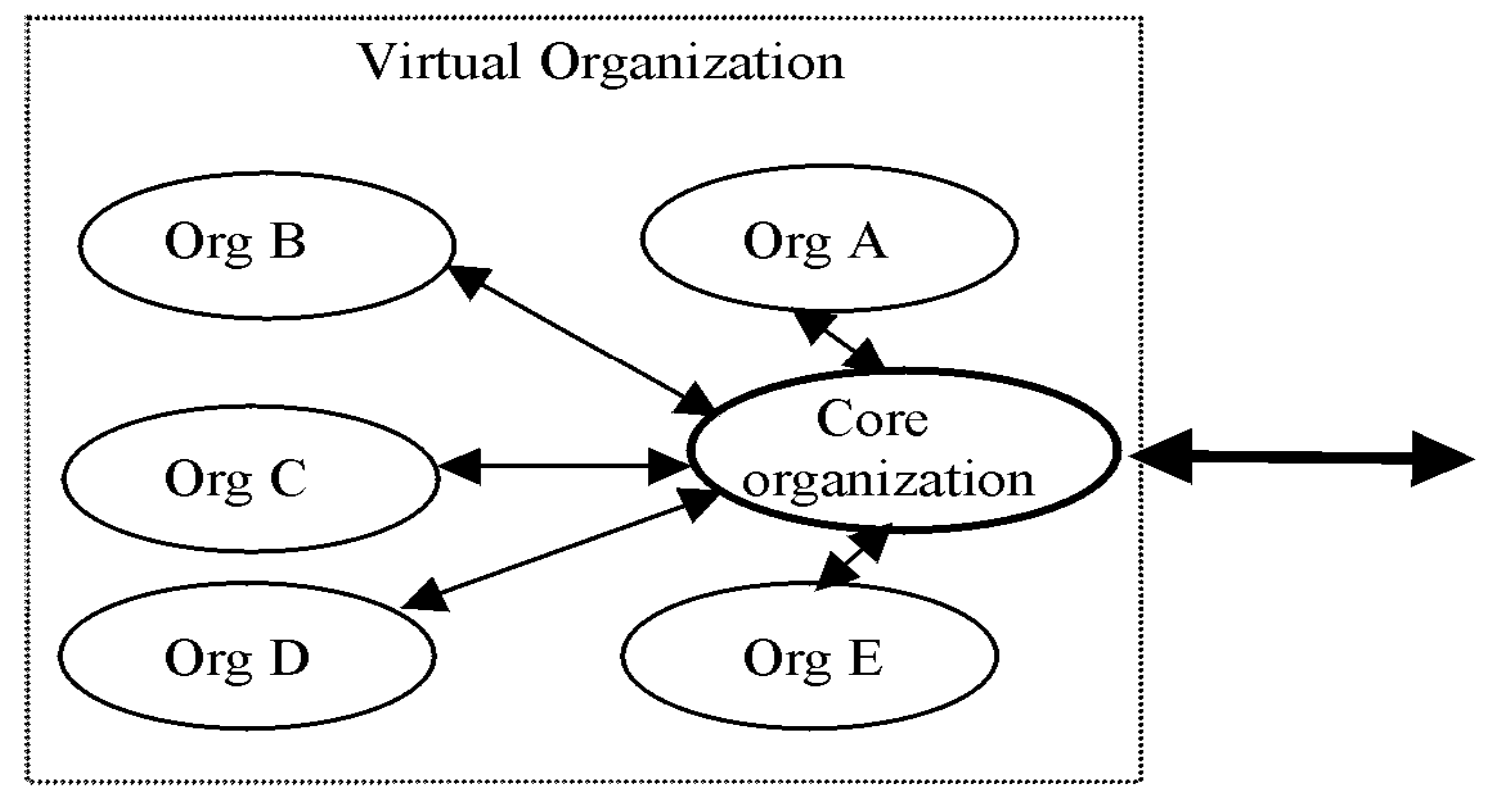

Custome core orge

\section{Market alliance}

Market alliances occur when a single organisation manages the relationships with customers. Market alliances are significantly different from star alliances regardless of their apparent structural similarity. The main difference is the 'star' of a star alliance is responsible for managing the whole of the virtual organisation, whereas the focus organisation in a market alliance only undertakes sales and marketing activities. A farm produce marketing association 
is an example of a market alliance: different farmers coordinate their production under the guidance of the marketing association, which also acts as an intermediary to customers.

In this situation, the ownership structure has a profound impact on the network's ability to become downstream market oriented. If control rests with the producers, the tendency is to make strategic and operative decisions that make life easy for the alliance members, while customers receive inferior service, products, and variety to choose from. Strategies tend toward forced membership of upstream suppliers in order to achieve monopoly powers. The e-system tends to exploit economies of scale, rationalization, and competition on price rather than value-added, differentiation and segmentation. Product and service innovation tends to be stifled, while administrative and production process innovations tend to be overly supported. The e-system tends to become control-oriented. If several market alliances compete, the alliance that manages to remain most downstream market oriented will normally become the customers' choice, but not necessarily the most profitable, dominant or competitive. The outcome depends on the heterogeneity and bargaining power of the customers relative to the same factors among the alliance members.

\section{Figure 5: Market alliance}

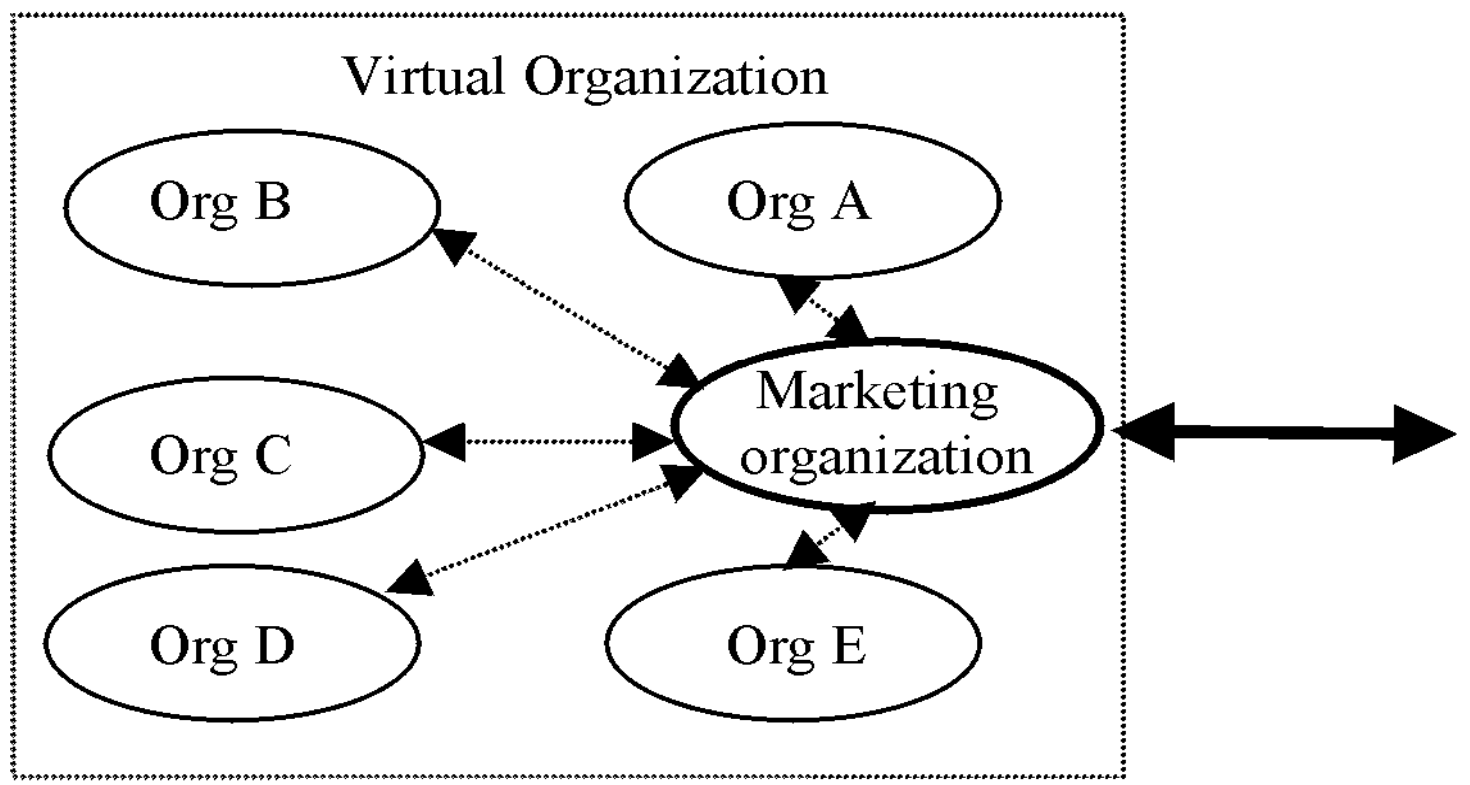

Custome market o

The dotted arrows signify that communication in the virtual operative network is only related to marketing and customer intelligence.

\section{Co-alliance}

Co- alliances occur where organisations participate equally in managing the virtual organisation and interacting with customers. Examples of co- alliances are when businesses manufacturing different mainly complementary goods within the same market collaborate to gain economies of scale, scope and coordination. In this case the leaders of the cooperating organizations either have to establish a governance and leadership organization over and above the co-alliance members, with some form of inter-organizational operational teams, or have one of the organizations take the lead on defining and developing the common elements 
and systems. Such alliances are inherently unstable, and tend towards full integration or revert to competitive market solutions (Lorange and Roos, 1992). In some cases the governance organisation originally established by the virtual space partners have developed into a new type of organisation that makes money by owning the marketplace, and selling access to sellers and buyers (see the above section on organising and owning a virtual market).

\section{Figure 6: Co-alliance}

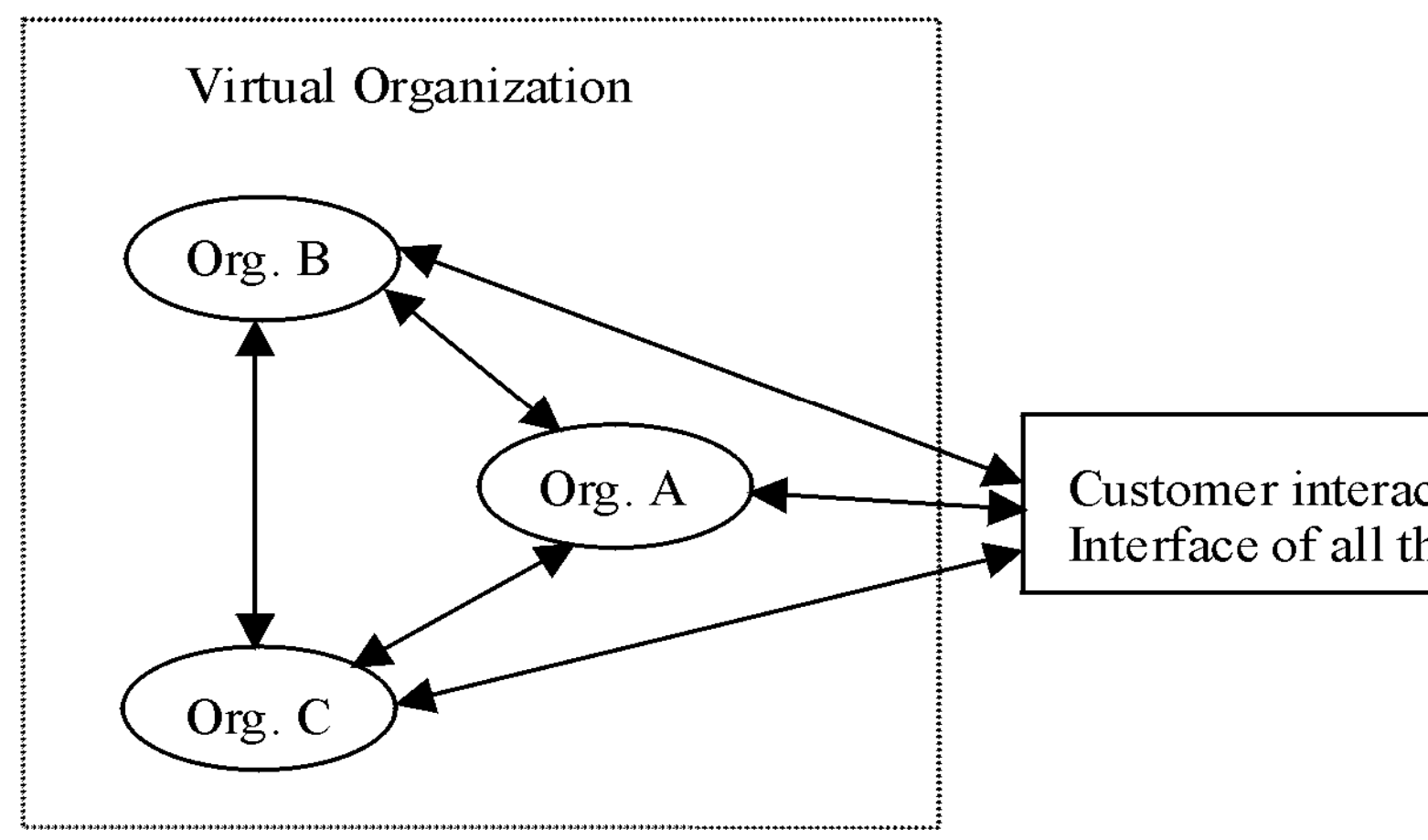

\section{Value alliance}

Organisations form themselves into a value alliance where there are benefits in integrating their value/supply chain. Value alliances are characterised by each member of the alliance adding value sequentially. The customer submits their order to the value chain, their order results in a flow of products through the value alliance. They are supplied from the organisation at the end of the value alliance chain. The value alliance \& supply chain is jointly managed and individual order management is sequential passed from one member of the value alliance to another as the product passes along the value chain.

A common form of value alliance is the organisation of businesses into a virtual market, e.g. for the manufacture of raw materials into goods. The end-of-the-chain organization carries the main burden of creating a corporate image and brands, and must be highly up- and downstream market oriented in order to play its leading role. The end-of-the-chain organization must ensure that the upstream organizations become sufficiently customeroriented, and take interest in developing the suppliers to become sufficiently integrated and competitive in the activities they undertake. Learning processes and e-solutions have to be integrated along the value chain through cooperative research and development. The e-system must allow for quick data throughput for value chain coordination. This type of network is inherently unstable, and will tend towards full merger or pure market-solutions at each stage of the value chain. The deciding factor is often whether the alliance manages to produce 
superior learning for adaptive and generative innovation in each critical activity. If superiority is achieved, merger normally follows. If one member organisation fails, it is often replaced.

Figure 7: Value alliance

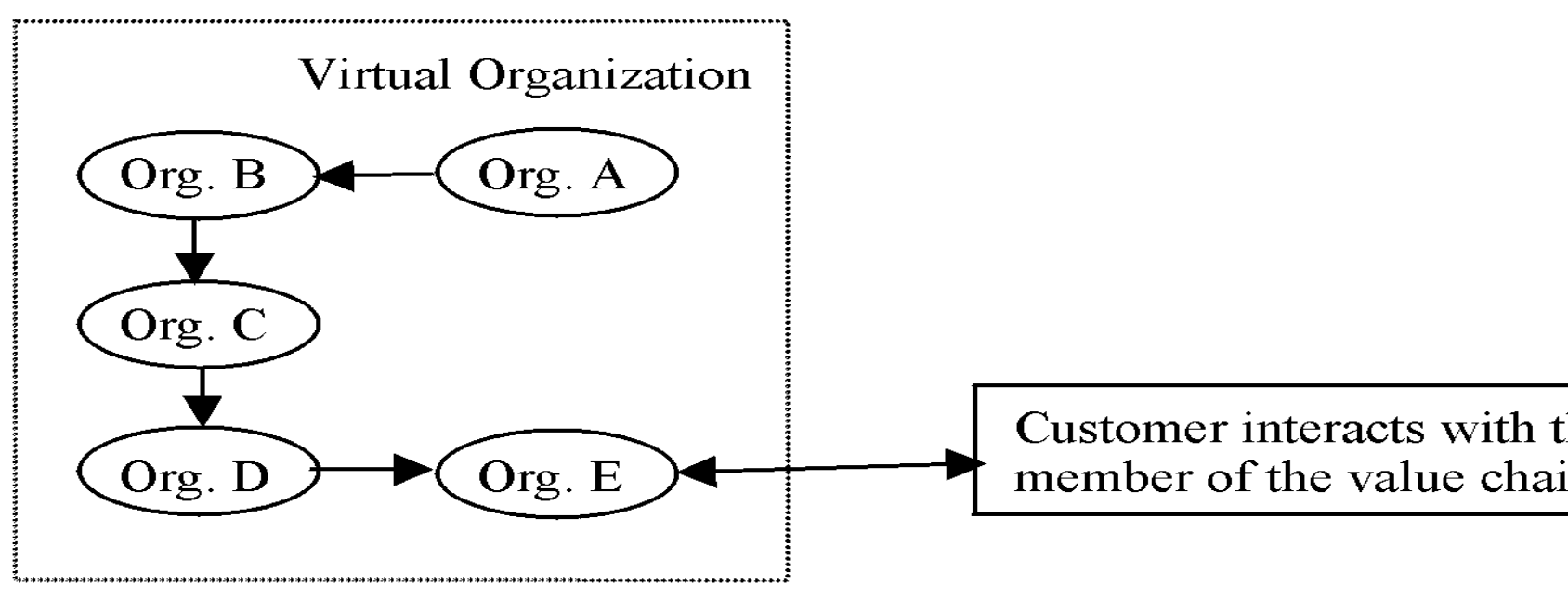

The arrows signify the main flow of goods and services. Payments and end-user market signals flow in the opposite direction. In terms of other types of communication the arrows would be interactive, but only along the value chain.

\section{Parallel alliance}

Parallel alliances occur when two or more organisations must work together because their output is interdependent. This arrangement is common in computer software and hardware fields where, for example, an operating system is written specifically to utilise facilities provided by a particular central processing unit chip. In this case, the customer must be taught that the alliance partners are cooperating and ensuring that the solutions work together.

The network needs horizontal links between the cooperating organizations at all activity levels, including in the market place that is visible to the consumer. The two or more cooperating organizations do not, however, have to establish any leader or a common culture. Each party can also make arrangements with any number of competitors to their alliance partner. If, however, the cooperation between the alliance partners leads to learning and innovations that are consistently superior to other cooperative arrangements the two have, the alliance will tend towards full merger, and the exclusion, for both parties, of other horizontal alliances. 


\section{Figure 8: Parallel alliance}

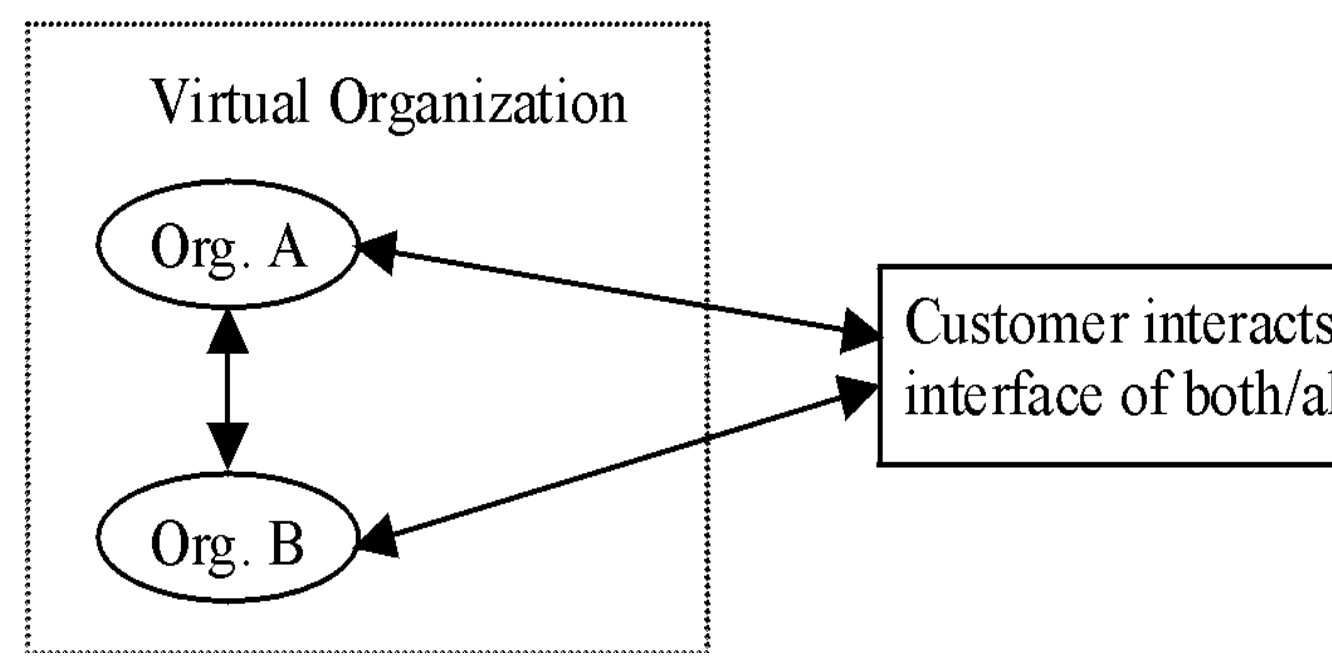

\section{Summary}

This paper brings together theories in Constituent Market Orientation and a taxonomy of virtual organisations. Combining these two theory streams has resulted in new and useful knowledge to support owners, developers, and managers of virtual organisations.

The paper outlines a way of analysing virtual organisations typical of e-business arrangements through the use of well-justified constituent market orientation theories. It provides managers of virtual organisations with analytically based heuristics founded on extensive cross-sectoral empirical research to guide their decision making and planning. Undertaking the above analyses points to the following key concepts:

- E-business and e-commerce is most often an extension of business that also takes place in the real world

- Real and virtual solutions have to work together, e.g. promote a common image, provide synergies etc.

- The extent of e-based solutions is dependent on the ability to convert tacit knowledge to automated e-systems and/or explicit knowledge at all user interfaces. Value creation that cannot be automated because of tacit knowledge has to be taken care of through real world exchange and production methods.

- Virtual e-business has to be supported by other real-world processes of leadership, cultural harmonization, and learning for innovations in administration, technology, know-how, systems, products, services, etc.

- Virtual solutions provide real world actors with newer data faster that can support organizational learning as well as operations. Virtual spaces should be configured to support natural on-the-job learning from systems-generated feedback. Virtual systems are limited in the ways they can assist project teams in interpreting data in the process of converting data to knowledge, understanding, problem solving and innovation.

- The need for one organization to take the on the leadership of an alliance depends on the nature of the alliance. The prime factor is the need to control and coordinate the interface with customers in order to provide a branding of the alliance in the minds of the consumers. This factor is independent of the degree of virtuality of the organization. 
Love, Terence (2003) Constituent market orientation and ownership of virtual marketplaces, Logistics Information Management 16(1):8-17.

- Alliances are inherently unstable and will tend toward totally administered solutions through mergers, or towards pure market solutions. The success or otherwise of alliance outcomes is likely to be often decided by the relative efficiency of learning and innovation within the alliance versus freedom of choice and competitive learning and innovation efficiency. The future competitiveness of any e-commerce solution is dependent on these learning and innovation processes that can only be supported by the data stream from the virtual system.

The paper adds a new category 'Owning and developing a virtual marketplace' to the earlier six-element typology of virtual organisations. This new category, a unique virtual organisational form in its own right, offers a generic model of which the original six elements are subcategories.

The approach presented in this paper has practical benefits in the ways that it enables the use of well-established and practically useful theories that support managing real world complex organisations in the development of theories about e-networking technologies and organisational structures:

- It establishes an improved context for successfully creating e-spaces (virtual organisations) and using them in real situations.

- It helps CEOs decide which virtual organisational structures are likely to be more successful in business terms.

- It offers a foundation for using the properties of e-networks

The paper draws attention to two interface issues important to virtual organisations:

- The interface whose purpose is the creation and governance of the virtual organisation.

- The placement of the e-system with respect to the other traditional real world production and transactional systems in industrial clusters.

The above practical and theoretical features imply that this approach to choosing virtual organisational structure supersedes prior methodologies whose predominant focus is on facilitating information management processes or providing technologically elegant solutions. Theories of constituent market orientation provide a foundation for understanding both traditional and virtual organisations, and any combinations of these, and thus provide a sound foundation for identifying successful organisational and management strategies and operational solutions.

\section{REFERENCES}

Amit, R. and Zott, C. (2001) "Value Creation in E-Business", Strategic Management Journal, Vol 22, pp. 493-520.

Burn, J. M. and Barnett, M. L. (1999) "Communicating for Advantage in the Virtual Organisation”, IEEE Transactions on Professional Communication, Vol 42 No 4, pp. 1-8.

Burn, J. M., Marshall, P. and Barnett, M. L. (2002) E-business Strategies for Virtual Organisations, Butterworth-Heinemann, Oxford 
Love, Terence (2003) Constituent market orientation and ownership of virtual marketplaces, Logistics Information Management 16(1):8-17.

Burn, J. M., Marshall, P. and Wild, M. (1999) “When Does Virtual have Value?”, In Romm, C. T. and Sudweeks, F. (Eds).Doing Business on the Internet: Opportunities and Pitfalls, Springer-Verlag, London.

Burn, J. M. and Tetteh, E. O. (2000) A Strategic Approach to the Development of an Infrastructure for Small and Medium E-Business, Presented at Bled E-Commerce Conference, Bled.

Conner, K. R. (1991) "A Historical Comparison of Resource-Based Theory and Five Schools of Thought Within Industrial Organization Economics: Do We Have a New Theory of Firm”, Journal of Management, Vol 17 No 1, pp. 121-154.

Crossan, M. M., Lane, H. W. and White, R. E. (1999) “An Organisational Learning Framework: From Intuition to Institution”, The Academy of Management Review, Vol 24 No 3, pp. 522-537.

Dahlstrom, R. and Nygaard, A. (1999) "An Empirical Investigation of Ex Post Transaction Costs in Franchised Distribution Channels”, Journal of Marketing Research, Vol 36 No 2.

Dutta, S. and Segev, A. (1999) "Business Transformation on the Internet”, European Management Journal, Vol 17, pp. 466-476

Hagel, J. III, and Armstrong, A. G. (1997) Net Gain: Expanding Markets through Virtual Communities, Harvard Business School Press, Boston, MA.

Heide, J. B. (1994) “Interorganisational governance in marketing channels”, Journal of Marketing, Vol 58 January, pp. 71-85.

Lethbridge, N. (2001) “An I-based Taxonomy of Virtual Organisations and the Implications for Effective Management”, Informing Science, Vol 4 No 1.

Lorange, P. and Roos, J. (1992) Strategic alliances: formation, implementation, and evolution, Blackwell Business, Cambridge, Mass, USA.

Marshall, P., McKay, J. and Burn, J. M. (2001) “The Three S”s of Virtual Organisations, Structure, Strategy and Success Factors”, In Barnes, S. and Hunt, B. (Eds), E-commerce and v-business : business models for global success, Butterworth-Heinemann, Oxford, pp. 171192.

Moran, P. and Ghoshal, S. (1999) "Markets, firms, and the process of economic development*, Academy of Management Review, Vol 24, pp. 390-412.

Prusak, L. (ed) 1997) Knowledge in Organisations, Butterworth-Heinmann.

Tellefsen, B. (1995) "Market Orientation in a Macro, Micro and Executive Perspective: Theory, Measurements and Empirical Evidence”, In Tellefesen, B. (Ed.), Market Orientation, Fagbokforlaget, Bergen, pp. 81-110.

Tellefsen, B. (1999) “Constituent Market Orientation”, Journal of Market Focused Management, Vol 4 No 2, pp. 103-124.

Timmers, P. (1998) "Business models for electronic markets”, Electronic Markets, Vol 8, pp. 3-8. 